\title{
Los centros comerciales en la ZMCM. Las empresas, localización y producción de un espacio urbano neoliberal
}

\author{
Shopping centers at ZMCM. The companies, location and production \\ of a neoliberal urban space
}

Dante Guillermo Celis Galindo ${ }^{1}$

http://orcid.org/0000-0002-8015-7918

Primera versión recibida: 15 de marzo de 2021

Última versión recibida: 28 de junio de 2021

\section{Resumen}

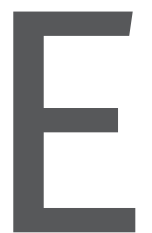

I presente trabajo tiene como objetivo analizar diferentes aspectos de los centros comerciales en la Zona Metropolitana de la Ciudad de México (ZMCM), como ubicación, año de apertura y empresa desarrolladora, así como identificar diversas características como etapas económicas y políticas en el país, además del papel que tienen las compañías urbanizadoras y los centros comerciales en la producción de un espacio urbano neoliberal. En el escrito, se muestra la manera en que los centros comerciales han crecido en importancia y se han convertido en una característica de la ciudad neoliberal; con ello, se visualizan y relacionan las características de estas obras urbanas con sus empresas constructoras y los gobiernos locales, lo que ha provocado la transformación de la ciudad. Después de realizar un censo, con más de doscientos centros comerciales, el estudio se limitó a aquellos que tuvieran mayor trascendencia por tamaño, localización y compañía desarrolladora. Al inicio del artículo, se mencionan las características que debían tener los centros comerciales para la realización de este trabajo. En un primer apartado se hace un acercamiento a los elementos teóricos de la ciudad

1 Universidad Nacional Autónoma de México. Profesor de asignatura en el Colegio de Geografía de la unAm. Líneas de investigación: Urbanismo; Fraccionamientos cerrados; Empresas urbanas; Centros comerciales; Deportes y ciencias sociales. Asistente en trabajos de investigación en El Colmich y la UAM-I en temas de Empresa y cooperativas; y Desarrollo urbano. Licenciado en Geografía por la UNAM; maestro en Geografía Humana por El Colmich; y doctor en Geografía por la UNAM.

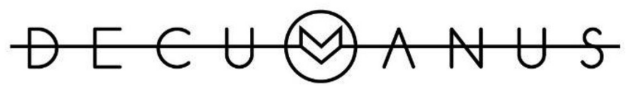

REVISTA INTERDISCIPLINARIA SOBRE ESTUDIOS URBANOS 
y del centro comercial con los que se identifican las urbanizadoras que más influyen en este proceso; en el segundo, se abordan las características de las plazas por localización y las características que las obras urbanas tienen según la zona donde estén; en el tercero, se analizan los años de apertura de las plazas y se relacionan con las administraciones gubernamentales y las características económicas que vivía el país; y, finalmente, se hace un recorrido por la reglamentación urbana en la Ciudad de México y sus últimas modificaciones.

Palabras clave: centro comercial; neoliberalismo; espacio; espacio urbano; empresa constructora.

\section{Abstract}

This work aims to analyze different aspects of shopping center at the Metropolitan Zone of Mexico City as location, opening year and developer company. Also it will identify diverse characteristics, economic and political phases in the country as well as the role of the development companies and shopping centers as a producers of a neoliberal urban space. This paper presents the way shopping centers importance has growth and how it had become in a neoliberal city characteristic; with this the characteristics of these urban works are visualized and related with their construction companies and local governments which has caused the transformation of the city. After conducting a census, with more than two hundred shopping centers, the study was delimited to those with the greatest significance by size, location and developer. At the beginning of the paper, the characteristics that shopping malls should have for the realization of this work are mentioned. In a first section an approach is made to the theoretical elements of the city and the shopping center and therefore identifying the developers that most influence this process; the second section addresses the characteristics of places by location and the characteristics that urban planners have depending on the area where they are; the third section discusses the years of opening, the squares and relates to government administrations and the economic characteristics of the country; and finally, a tour of the urban regulations in Mexico City and its latest modifications is made.

Keywords: shopping center; neoliberalism; space; urban space; construction company.

\section{Introducción}

Existe una gran variedad de centros comerciales (cc) y diferentes maneras de clasificarlos: por extensión territorial; por época de construcción; por tiendas; por arquitectura; por nivel socioeconómico; entre otras. Cada persona o institución que ha analizado los cc presenta características propias en su estudio para mostrar una delimitación.

El presente trabajo surge del objetivo general de analizar aspectos como la ubicación, año de apertura y empresa desarrolladora de los cc en la Zona Metropolitana de la Ciudad de México (zмcm), además de identificar diversas características de las etapas económicas y políticas en el país.

Una parte importante del documento es identificar el papel de las empresas urbanizadoras, que son las que construyen obras o infraestructura urbana, ya que asumen un

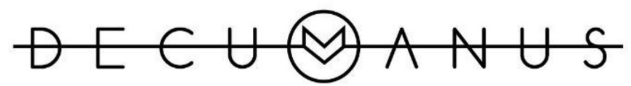

REVISTA INTERDISCIPLINARIA SOBRE ESTUDIOS URBANOS 
rol fundamental en la producción de un espacio neoliberal, pues planifican, construyen o modifican el entorno. Para identificar a estas compañías, sus estructuras e influencia en la ciudad es que se levantó un censo de cc, a partir de recorridos, datos gubernamentales y exploración electrónica, con lo que se identificaron más de doscientos, cifra similar a la que se menciona en los trabajos de Emilio Pradilla (2008), Cruz (2008) y José Gasca (2017), aunque cada uno de ellos utiliza una metodología propia.

Como una segunda etapa, se estableció una limitación propia en la que se consideró una extensión territorial superior a los $1000 \mathrm{~m}^{2}$; que cuenten, al menos, con una tienda ancla; que tuvieran la cobertura de alimentos, ropa, servicios financieros, lugares de entretenimiento y espacios deportivos, ya que estos son los elementos principales que buscan los consumidores. Con estas características se identificaron 132 cc en la ZMCM y de estos, se identificaron los de mayor influencia urbana y económica en la zona donde se localizan, a lo que se denominó plazas grandes.

Con la delimitación se identificaron los patrones de localización, empresa desarrolladora, año de apertura y tiendas ancla, lo cual permitió reconocer las características que tenían los cc según la etapa económica del país, así como distinguir las relaciones empresariales con los distintos niveles de gobierno y los partidos que ostentaban el poder político. Además, se puede identificar la influencia que tienen las compañías urbanizadoras para producir una ciudad con características neoliberales.

Los Cc, con estas características, evidencian la influencia de las empresas urbanizadoras en la construcción de la ciudad, el capital invertido, las relaciones económicas y políticas, la evidencia de una transformación económica y las características sociales actuales.

\section{Empresa urbanizadora en el neoliberalismo: un contexto teórico}

Dentro de la etapa neoliberal el suelo urbano adquiere mayor importancia, ya que se considera un bien escaso, por lo que es común que los inversionistas busquen diversas maneras para conseguirlo y explotarlo económicamente. Pero cada empresa inmobiliaria modificará el suelo según sus objetivos, lo que provocará que el sector privado tenga cada vez mayor peso en la generación de una ciudad que se mostrará fragmentada. La ZMCM tiene precisamente esas características que se han vuelto representativas de una ciudad neoliberal.

En la ciudad neoliberal el suelo está estrechamente relacionado con la renta, la cual es resultado de las relaciones sociales que ponen un precio a la porción de la tierra de la que se trate y que va acorde con las actividades que ahí se generen y con la capacidad de obtener plusvalía, que es el excedente monetario que va para el inversor (Jaramillo, 2008, pp. 4-6). Las actividades que más elevan las rentas son las comerciales; es por ello que los agentes urbanos buscan imponer en sus obras urbanas elementos como los cc. Los inversionistas, si bien no son quienes establecen la renta, sí asumen un papel significativo al generar construcciones que se instalan entre la sociedad como elementos de mejora en infraestructura y de generación de "estatus", aunque para esto se necesiten producir cambios rápidos y constantes en las ciudades.

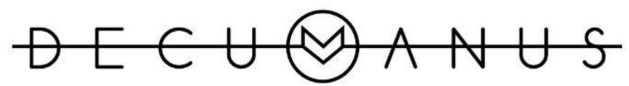

REVISTA INTERDISCIPLINARIA SOBRE ESTUDIOS URBANOS 
La renta, según Robert y Messias (2009, p. 104), es una de las máximas expresiones del capitalismo y, en general, de la propiedad privada del espacio. Mientras que Harvey (1990, pp. 333-335) menciona que es el pago que se le hace al dueño de una parcela del terreno, en la que interviene de una forma primordial la ubicación, pues esta puede aumentar o disminuir dicho pago. Aunque en el caso de los cc las rentas pueden elevarse cuando se realizan estructuras que brinden algo totalmente ajeno a su espacio circundante, por ejemplo, al oriente de la ciudad con Plaza Jardín en Nezahualcóyotl, ya que, según los inversores, esta obra ayuda a la población a librarse de los conflictos de inseguridad que se viven al exterior.

Dentro del neoliberalismo las empresas urbanas invierten en diversas áreas de la ciudad, lo que les permitirá acceder a una ganancia en forma de renta, ya que para ellas es importante generar presencia en la urbe y así evitar que aparezca una posible competencia que merme sus ganancias (Robert, \& Messias, 2009, p. 102). Las empresas que desarrollan cc eligen, en dependencia de la zona de la ciudad, la arquitectura, las tiendas y el capital simbólico del interior de los Cc, ya que estos elementos asumen un papel fundamental en la generación o elevación de la renta (Harvey, 2005, p. 48).

En la ciudad neoliberal la localización de los cc está asociada con la obtención de la renta, por lo que el inversor busca una zona que le brinde mejores beneficios como la posibilidad de una mayor generación de plusvalor; eso es en parte el motivo de la actual expansión de la Ciudad de México y de la proliferación de cc. Aunque un elemento principal para la localización de un cc es la importancia o la influencia de la empresa urbana, es por ello que las firmas de mayor importancia, como Carso, Danhos, Sordo Madaleno, Mexico Retail Properties (MRP) (Gráfica 1), son las que más cc tienen en la ciudad.

\section{Gráfica 1. Centros comerciales por urbanizadora. Número de plazas por empresa}

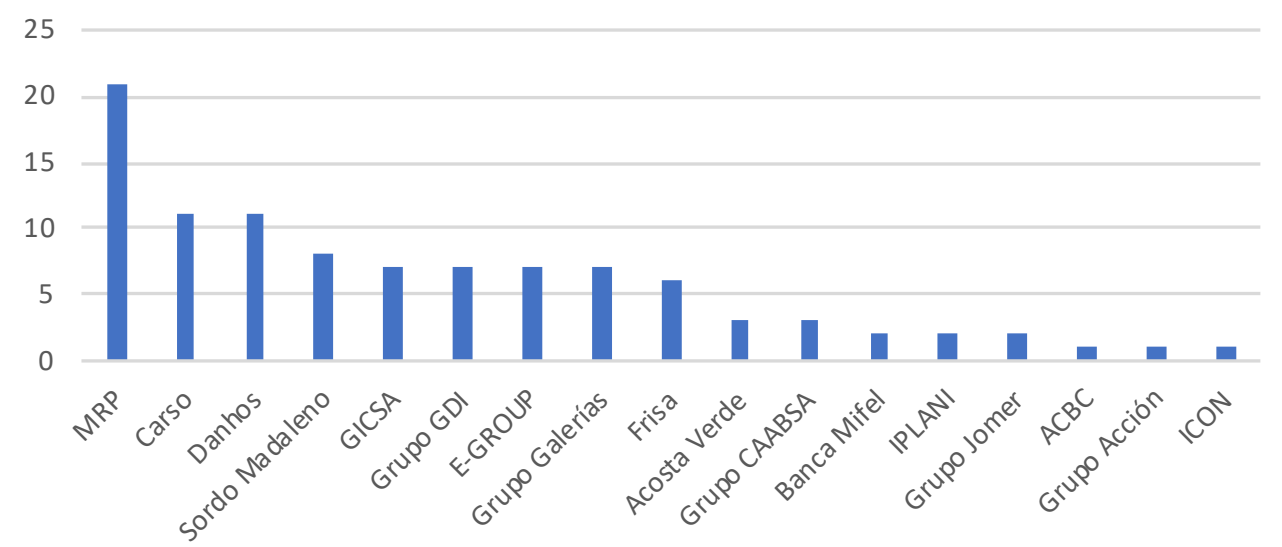

Fuente: elaboración propia, a partir del levantamiento del censo propio.

La importancia de una empresa le permitirá acceder a la mejor localización, que es un elemento primordial para la obtención de renta en el entorno urbano; así lo mencionan Robert y Messias (2009, pp. 104-105), al definir este proceso como una renta diferencial que basa sus ganancias en las cualidades, físicas o sociales, de un lugar; además, ejemplifican que en la cuestión urbana la diferencia en la localización provoca que el valor

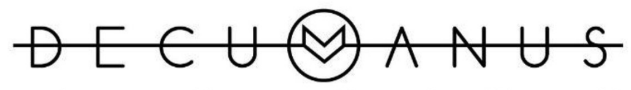

REVISTA INTERDISCIPLINARIA SOBRE ESTUDIOS URBANOS 
crezca o disminuya. Es por ello que la búsqueda de un "mejor" lugar es primordial para los desarrolladores urbanos y la localización es uno de los elementos más importantes para la construcción del cc.

\section{Patrones de localización de los centros comerciales en la ZMCM}

Los primeros cc en el país, se edifican al final de la década de 1960 con Plaza Universidad en el Distrito Federal y Plaza Satélite en el Estado de México (además de Plaza del Sol en Guadalajara). El aumento de la población, la expansión territorial de la ciudad y la desigualdad económica ayudaron a generar la necesidad de aumentar la oferta del cc, que, paulatinamente, se convierte en una característica de la ciudad neoliberal (Pradilla, 2012, pp. 225-227). Los CC, en el periodo neoliberal, funcionan como detonador de crecimiento urbano o económico, por lo que se ha vuelto común que se edifiquen en zonas aparentemente alejadas de un núcleo urbano, lo que ha provocado que no sea solo visto como un aglutinador de comercio, sino como una infraestructura urbana compleja en la que la localización es uno de los elementos más importantes.

La localización de los CC en la ZMCM tiene estrecha relación con la temporalidad en la que fueron construidos y con la empresa desarrolladora. Los niveles de gobierno también están involucrados, ya que en ocasiones facilitan el acceso al terreno, realizan los accesos, generan los cambios de usos de suelo, si es que son necesarios, entre otras cuestiones. La localización del cc es fundamental y depende de diversos factores; anteriormente se buscaba acceso a un predio inhabitado, se llevaban a cabo diversos estudios de mercado para identificar su potencial comercial y, si este resultaba redituable, se procedía a la compra del terrenos o inmuebles. Sin embargo, actualmente se busca una zona específica donde el nivel socioeconómico de la población circundante y las ganancias potenciales que la zona puede otorgar, se convierten en los elementos principales para proyectar un CC, además de las facilidades que brinden los distintos tipos de gobierno.

Por las características anteriores es que se considera que la construcción de cc corresponde a prácticas típicas del neoliberalismo, pues la producción de espacios que permitan cumplir los objetivos de acumulación de capital es imperante para que el neoliberalismo se fortalezca. Por lo que, como se verá a continuación, la ubicación y la etapa en la que se construyen los cc están estrechamente relacionadas. Las etapas de construcción muestran también la forma en que se van edificando estas obras urbanas por zonas de la ciudad.

Del total de las plazas analizadas en este trabajo, ochenta y una se localizan en lo que hasta 2018 fue el Distrito Federal y cincuenta y una en los municipios pertenecientes al Estado de México. En ambas administraciones los cc muestran tendencias en su localización, porque las vías de comunicación se convierten en elementos principales, ya que la gran mayoría de los cc en esta ciudad están edificados sobre las vialidades primarias. En el Estado de México, la localización es primordialmente sobre las carreteras federales y autopistas o, en su defecto, sobre vialidades secundarias que tienen conexión directa con las primeras, aunque este tipo de localización corresponde a cc aislados o, por el contrario, que aglutinen más de dos plazas para aumentar la oferta. La localización principal está sobre las carreteras que comunican a la Ciudad de México con Querétaro y Puebla, además del anillo periférico donde también se localiza una alta tendencia para la cons-

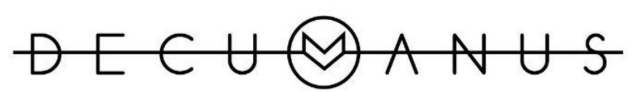

REVISTA INTERDISCIPLINARIA SOBRE ESTUDIOS URBANOS 
trucción de plazas. La mayor densidad está en los municipios de Naucalpan y Cuautitlán Izcalli. Solo en Huixquilucan la ubicación es diferente, ya que conforma otro centro de alta densidad de plazas (Mapa 1; Gráfica 2).

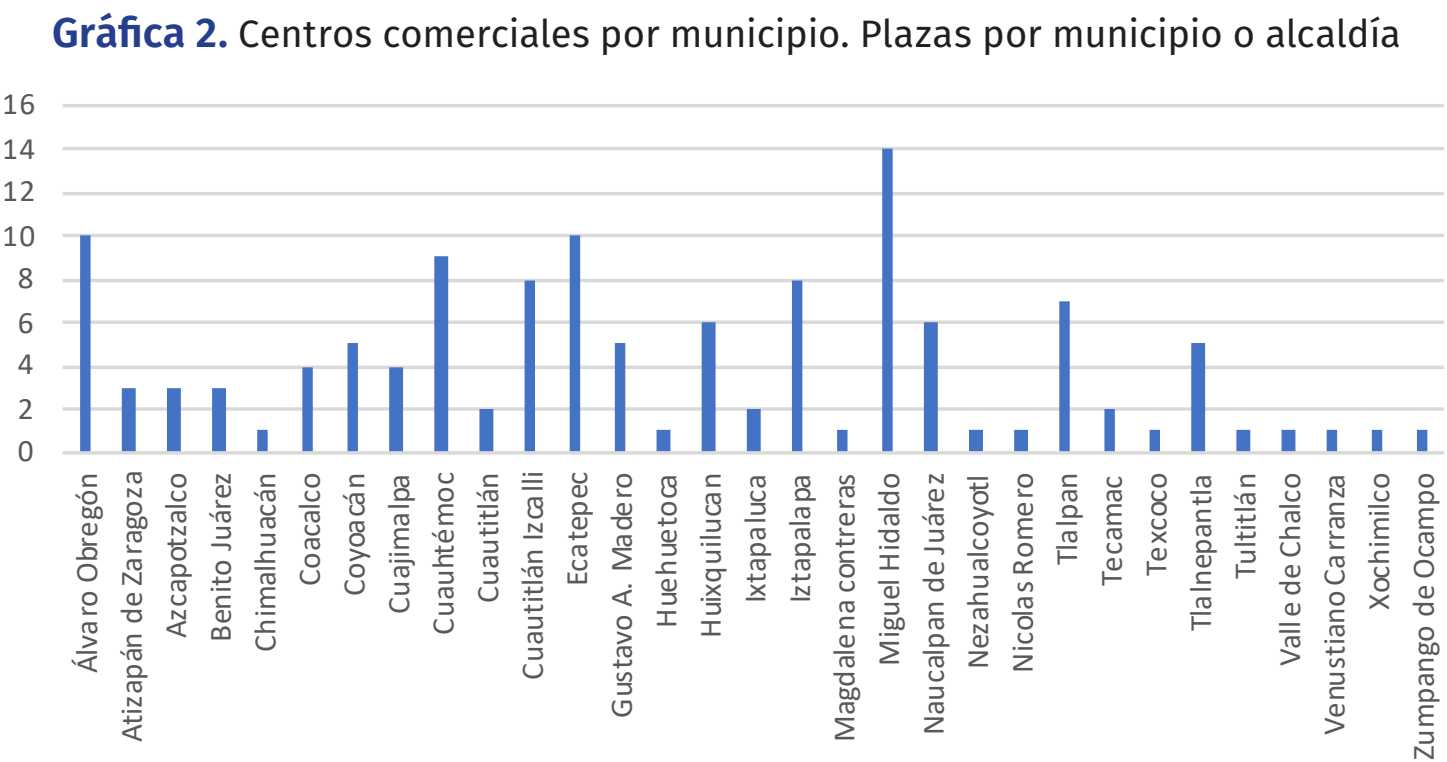

Fuente: elaboración propia, a partir del levantamiento del censo propio.

En los límites de la Ciudad de México, las principales avenidas en las que se localizan cc son las que cruzan la ciudad de sur a norte, como Insurgentes, Cuauhtémoc o Eje 1 Poniente con la continuación de la Avenida Universidad y, con una menor concentración, la Avenida Revolución. Sobre estas tres vialidades se localizan 31 cc. Existen algunos inmuebles relativamente nuevos que se construyeron alejados de la principal aglomeración comercial, como Las Antenas, que rompe completamente con la tendencia de construir corredores o centralidades comerciales, ya que este se localiza al extremo sur de la ciudad. En los municipios conurbados se sigue con la misma tendencia, ya que las principales avenidas sobre las que se construye son las que unen al otrora Distrito Federal con el Estado de México, como Periférico Norte y Avenida Central, o se edifican en zonas como Huixquilucan en las que se busca generar una nueva centralidad.

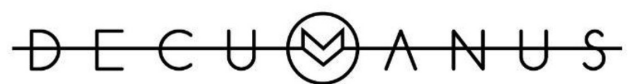

REVISTA INTERDISCIPLINARIA SOBRE ESTUDIOS URBANOS 
Mapa 1. Ubicación de los centros comerciales en la ZMCM

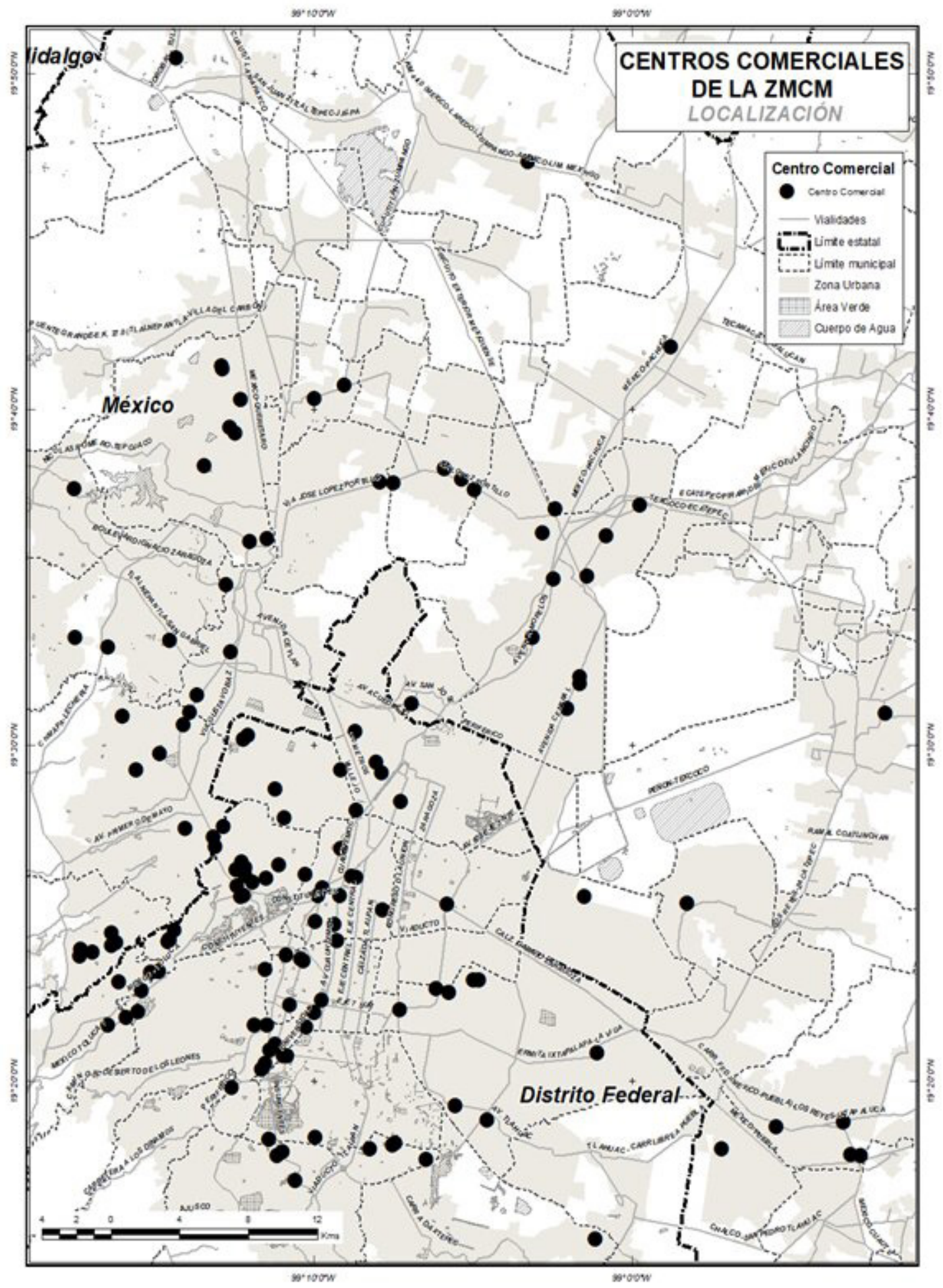

Fuente: elaboración propia, a partir del levantamiento del censo propio.

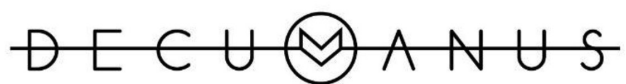

REVISTA INTERDISCIPLINARIA SOBRE ESTUDIOS URBANOS 
Existen también algunos desarrollos en Miguel Hidalgo, Álvaro Obregón y Cuajimalpa, donde las vías de comunicación no son los elementos principales para la localización, sino el estrato socioeconómico de la población residente. En el resto de la ciudad, los cc se ubican con mayor dispersión y responden a otro tipo de características, como la inversión o rescate de zonas que se identifican, por parte del gobierno local, como conflictivas, y en las que se aprovecha y se tiene estrecha relación con los medios de transporte, como los Centros de Transferencia Modal (Cetram). Todo lo anterior ocurre principalmente en Gustavo A. Madero, Azcapotzalco, Ecatepec y Nezahualcóyotl, donde la mayoría de los cc corresponden a planes gubernamentales o empresariales de mejoramiento de una zona, como los paraderos de El Rosario y el de Ciudad Azteca, o como Ciudad Jardín en Nezahualcóyotl.

La localización es fundamental para edificar y clasificar un Cc. El Consejo Internacional de Centros Comerciales (ICSC, por sus siglas en inglés) y la Asociación Española de Centros Comerciales $(\mathrm{AECC})$ consideran la ubicación como fundamental para proyectar el éxito de una nueva edificación. Estas dos organizaciones consideran la superficie territorial; tiendas; centros de vecindad; centros de comunidad; centros suprarregionales; centros temáticos o de festival; y los outlet centers (Escudero, 2008, pp. 44-45).

Según todas las características anteriores es que se clasifican los cc y, como resultado, se caracterizan como fashion centers y life-style centers, que suelen ser los cc de mayor dimensión territorial en los que, aunque existe una diversidad de productos, hay tiendas departamentales de lujo (Escudero, 2008, p. 44) y que, por lo general, son los que suelen ser los de mayores repercusiones urbanas; los power centers, que son cc dedicados a la venta de productos de bajo costo, o con ofertas, los cuales por lo general pueden estar especializados en no más de tres diferentes tipos de productos (Escudero, 2008, p. 44), aunque suelen ser tiendas de gran prestigio y son las que más proliferaron en la década de 1990 cuando la crisis económica azotó a México; los de usos mixtos, que son la tendencia actual, ya que los cc van acompañados o acompañan a otro tipo de construcciones, como viviendas, edificios corporativos, comercios especializados o transporte público; así encontramos en México los mix commercial y usos mixtos. Los regional mall suelen ser los de mayor tamaño y tienen distintas tiendas con diferentes rubros, pero relacionadas entre sí, y a su vez se subdividen en centros de vecindad; centros de comunidad; centros suprarregionales; centros temáticos o de festival (Escudero, 2008, pp. 44-45).

En porcentaje de superficie rentable, el tipo de cc que predomina en México son los de community center, life-style y power center (Gasca, 2017, pp. 13-14), que son precisamente los que realizan los grupos desarrolladores más importantes de México (Gasca, 2017, pp. 13-14) (Gráfica 3).

Los Cc de mayor tamaño, y que representan una mayor generación de ganancias, están distribuidos en prácticamente toda la ZMCM, aunque son más continuos en la parte norte y poniente de esta. Casi todas las empresas urbanizadoras de mayor capacidad inversora cuentan con este tipo de CC, como FIBRA Danhos; Carso; Grupo Sordo Madaleno; MRP; e-Group, Gicsa y Frisa, y también aparecen otros que comienzan a tener importancia, como Banca Mifel y Grupo Acosta Verde. Del total de los grandes cc que aquí se consideran veinticuatro se localizan dentro de los límites de la Ciudad de México, mientras que veinte están en los municipios conurbados. Esto demuestra que, a pesar de ser administraciones diferentes, el impulso a este tipo de obras urbanas es igual.

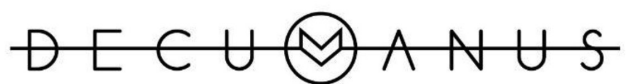

REVISTA INTERDISCIPLINARIA SOBRE ESTUDIOS URBANOS 
Gráfica 3. Porcentaje de superficie rentable de los diferentes tipos de centro comercial en México respecto al total del terreno ocupado por centro comercial. Poncentaje en superficie

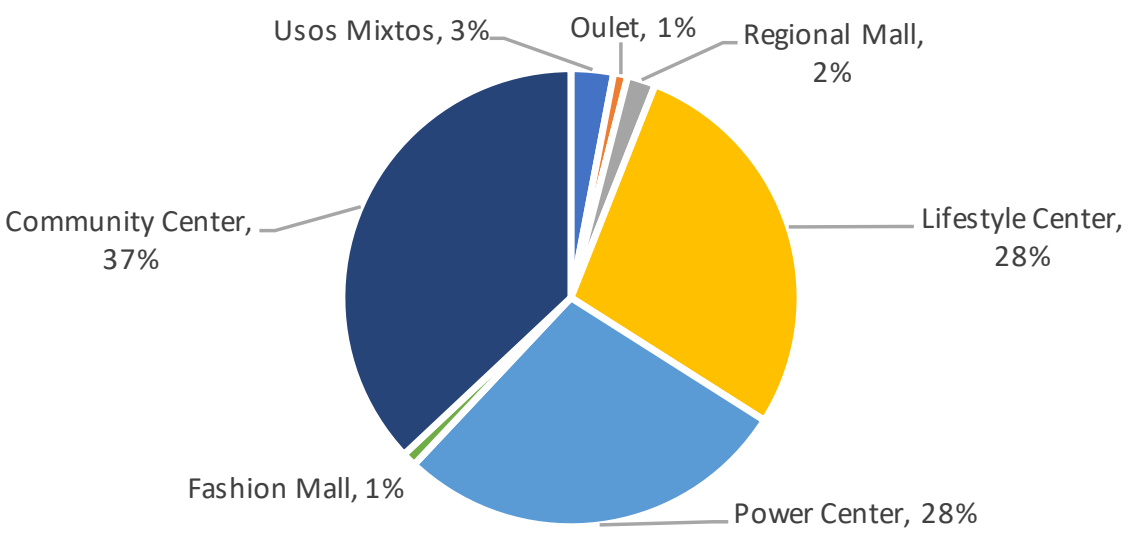

Fuente: CBRE México 2016; en: Gasca (2017), p. 14, Cuadro 3.

La mayoría de estas plazas fueron detonantes urbanos y sirvieron como polos de atracción de otras urbanizaciones o como complementos de regeneración urbana propuesta por el gobierno de la Ciudad de México. Por lo tanto, estas plazas son las que más han contribuido a desarrollar partes de la ciudad o, al menos, a elevar la renta y plusvalía de la zona; y con ello se han encarecido los usos del suelo y modificado las dinámicas económicas y sociales locales.

La construcción y masificación de los grandes cc también acarrea como consecuencia que pierdan su unicidad y se requiera algún otro elemento de distinción, como pueden ser el acceso, la vialidad, la ubicación, el servicio, las tiendas al interior, etcétera. Un ejemplo claro es Plaza Oasis Coyoacán, que compite con varias plazas más en la zona y con tiendas de autoservicio, pues en el predio de enfrente existe un Wal-Mart, y a no más de un kilómetro se encuentra otro al sur; además, en la zona hay servicios financieros, comida rápida, librerías, que aunque no están aglomerados en una plaza sí se localiza prácticamente todo, mientras que a no más de tres kilómetros está el cc Coyoacán. Para competir los desarrolladores generaron atracciones en la arquitectura, en la que incluyen un lago artificial de $3500 \mathrm{~m}^{2}$.

Las formas de distinción también ayudan con la imagen de una ciudad competitiva y global, ya que en ocasiones se realizan novedades que siguen patrones internacionales; por ello, es una tendencia a nivel mundial el uso de fuentes o lagos artificiales como parte de la nueva oferta comercial.

Es también común que los cc grandes sean las edificaciones que más hayan aprovechado el cambio económico que generó el final de la industrialización, ya que esos antiguos terrenos se han convertido en un punto de partida o de consolidación de las nuevas centralidades o de centros urbanos. Las centralidades son lugares que tienen aglutinados múltiples funciones, como las financieras, comerciales, vivienda y trabajo, y surgen para facilitar la dispersión de ofertas y que la población tenga la posibilidad de satisfacer sus necesidades en diferentes lugares de la ciudad, con lo cual estos cc van creciendo en im-

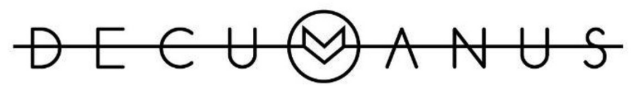

REVISTA INTERDISCIPLINARIA SOBRE ESTUDIOS URBANOS 
portancia económica y hasta política y urbana, y es común que sus construcciones sean en lugares donde se sustituye otra actividad económica o una empresa que en el pasado tuvo gran influencia y significación económica, pero que esta se ha perdido.

Algunas de estas nuevas centralidades son, por ejemplo, el complejo que ocupa Plaza Carso y Antara, que anteriormente fue la fábrica de General Motors; o los terrenos que ocupan Plaza Inbursa y Loreto, que fueron fábricas de papel. Además, Plaza Fórum Buenavista, si bien no fue una fábrica sino la estación del ferrocarril sí vivió en la etapa industrial su época de auge. Estos cambios evidencian el avance terciario de la producción espacial urbana y el "mejoramiento" territorial de esas zonas con la inversión inmobiliaria. Pero no solo es la suplantación del modelo laboral lo que se modifica, sino también la cotidianidad de la sociedad y los espacios de entretenimiento, ya que varios espacios dedicados al esparcimiento popular fueron suplantados por grandes cc, como Parque Delta y El Toreo; incluso terrenos cercanos a zonas protegidas por su valor histórico y simbólico han sido modificados en pro de los grandes comercios, como Plaza Inbursa localizada cerca de la Zona Arqueológica de Cuicuilco. A través de los cc es que los empresarios urbanos, se convierten en actores fundamentales de la producción de un espacio urbano neoliberal característico de esta época.

Los grandes CC, en la ZMCM, han sido construidos en terrenos donde no existía una actividad evidente, como en Ixtapaluca o Ecatepec, o donde la antigua actividad ya no era redituable; también han suplantado la actividad que se realizaba mediante la fuerza económica de los grupos desarrolladores y la emisión de los permisos por parte de las autoridades locales. La inversión en lo urbano también ha sido parte de una estrategia de los grandes poseedores del capital mediante la cual se superan las crisis económicas, ya que se piensa que la población siempre necesitará un lugar donde vivir y hará uso del capital financiero para consumir en los cc.

El interés por construir centros de especialización alejados del antiguo centro de la ciudad es parte de los resultados de la expansión urbana y de los problemas de conectividad de la ZMCM. Por lo tanto, es necesario ofertar los servicios necesarios en las áreas más alejadas del centro de la ciudad, pero la oferta incluye la construcción de nuevos cc, casi todos estos casos con una tienda de autoservicio como ancla. La construcción de nuevas centralidades se da también en las zonas de mayor plusvalía de la ZMCM, donde aparentemente no cubrirían una carencia social, y son poco construidos en las áreas más alejadas de la ZMCM.

Al inicio los grandes cc se caracterizaron por ser construidos en zonas donde la población local pertenece a las clases altas y medias altas, y por lo tanto, los primeros estuvieron muy apartados entre sí: Plaza Universidad, sobre la avenida del mismo nombre, al sur de la ciudad; Plaza Satélite, localizada en el norponiente de la ZMCM en lo que en ese momento era el límite territorial de la ciudad; Multiplaza Aragón, al oriente de la ciudad, en una de las zonas que comenzaba a poblarse cuando esta se edificó; Perisur, al extremo sur de la ciudad en la confluencia de las avenidas Insurgentes y Periférico, el cual brindaba su servicio a la población que ya se había alejado completamente del centro de la ciudad; y Pabellón Polanco, en la zona del mismo nombre. Todas estas plazas se inauguraron antes de 1990 y tenían grandes áreas de influencia, por lo que representaron casos

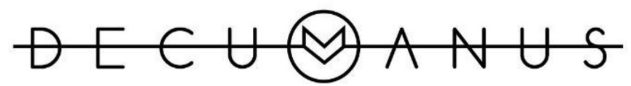

REVISTA INTERDISCIPLINARIA SOBRE ESTUDIOS URBANOS
Núm. 7. Vol. 7. Mayo 2021-Octubre 2021. Instituto de Arquitectura, Diseño y Arte. Universidad Autónoma de Ciudad Juárez. ISSN: 2448-900X 
de éxito, a pesar de las etapas de recesión económica que se vivieron en el país. Esta se define como una primera etapa.

A partir del inicio del siglo XxI son las plazas grandes las que continúan marcando la pauta del tipo de urbanización que tiende al comercio; además, son las que ayudan a propiciar el aumento de plusvalía y de renta en la zona, por lo cual las instituciones gubernamentales propician este tipo de construcciones en diferentes áreas de la ciudad; este patrón se sigue en las dos administraciones estatales de la ZMCM, aunque con una limitante sustancial que es la carencia de territorio disponible para realizar las obras.

En la etapa neoliberal las empresas constructoras se convirtieron en productores de la ciudad, debido a que este rubro es atractivo para las inmobiliarias por las ganancias que generan. Esto provoca que exista un mayor número de empresas que busquen terrenos para invertir, lo que a su vez ocasiona que la ciudad se fragmente según las necesidades y características de cada compañía constructora. Cualquier nueva edificación presenta un impacto en el espacio circundante, ya sea en la simple cuestión física o en lo económico, e incluso en lo social. Los cc se convierten en una centralidad económica y comercial, por lo que impactan en gran manera en el entorno urbano.

Los cc que más impacto generan son los de mayor dimensión territorial y los que producen mayores ganancias. Varios de esos Cc, se localizan en zonas de transición económica y dispersas por toda la ZMCM. La Ciudad de México es completamente heterogénea y los cc funcionan como regeneradores urbanos o como punto de partida de grandes consorcios terciarios, pero no necesariamente como parte de una mejora en la calidad de vida de las personas, ya que donde se localizan, además de encarecer el suelo y diversos costos, el nivel de vida continúa de la misma manera que antes de la construcción de los mismos. Las plazas donde este proceso es más evidente es en Gran Terraza, Multiplaza Arboledas, Parque Tezontle, Torres de Lindavista, San Marcos Power Center, Patio Interlomas, Ciudad Jardín, Sendero Ecatepec, Gran Patio Texcoco y Plaza Central, localizadas en distintas zonas de la ciudad; la mayoría en vialidades principales (Mapa 2).

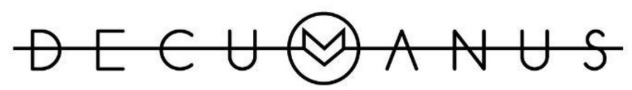

REVISTA INTERDISCIPLINARIA SOBRE ESTUDIOS URBANOS 
Mapa 2. Grandes centros comerciales formadores de nuevas centralidades

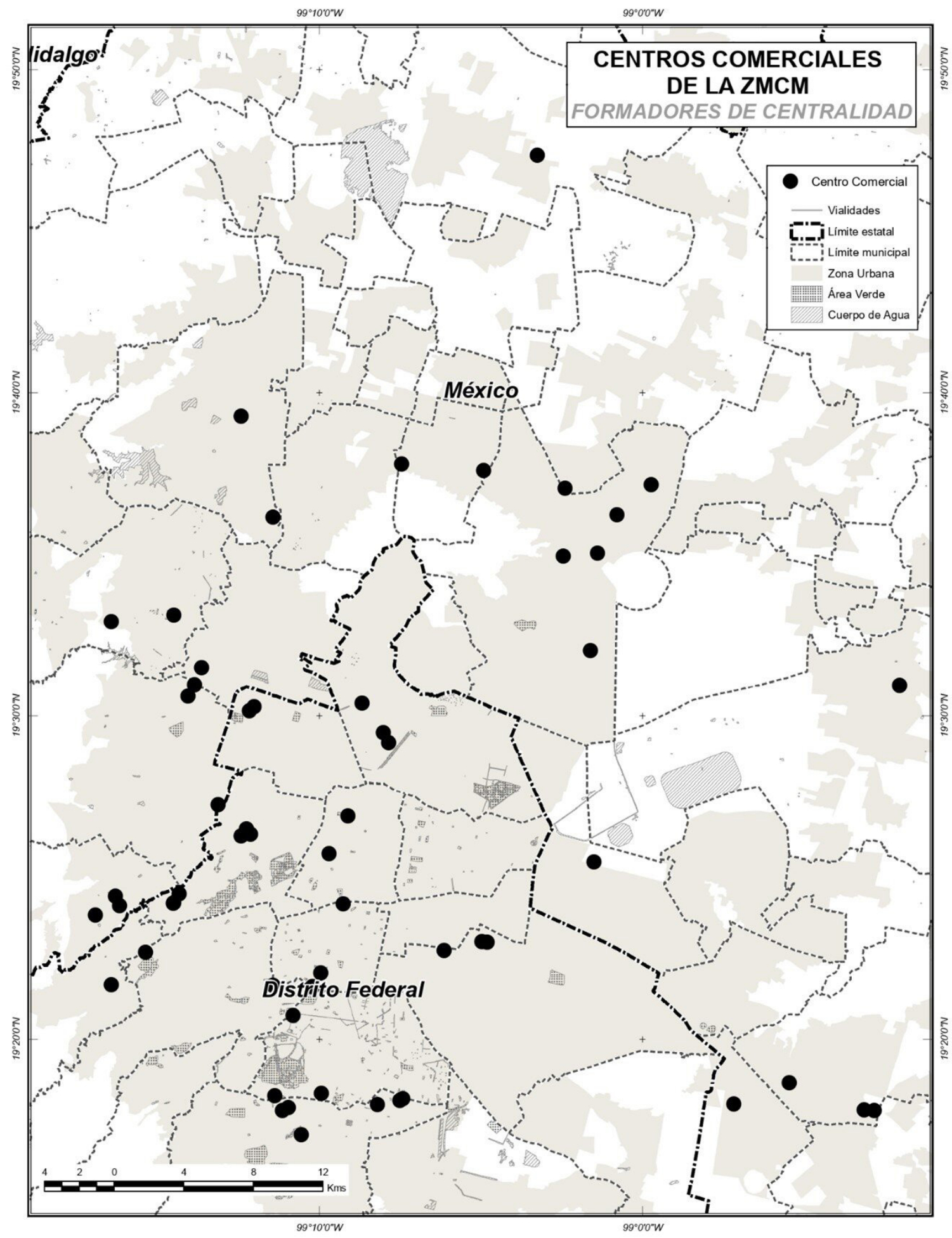

Fuente: elaboración propia, a partir del levantamiento del censo propio.

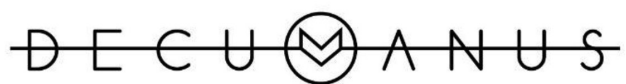

REVISTA INTERDISCIPLINARIA SOBRE ESTUDIOS URBANOS 
La división en sectores económicos brindará a los inversores inmobiliarios la posibilidad de escoger el tipo de tiendas que se establezcan en la nueva construcción. Sin embargo, existen inmobiliarias que tienen contratos preestablecidos con algunas firmas, como es el caso de Wal-Mart con MRP, lo que hace que todas las construcciones de esta inmobiliaria tengan como ancla esta cadena de autoservicio.

La tienda ancla, entonces, se convertirá en un elemento distintivo y, también, va en relación con la ubicación. En las zonas medias-altas y altas todos los cc grandes cuentan con una tienda departamental como su principal comercio, como El Palacio de Hierro, Liverpool o Sears, e incluso dos de ellas. Mientras que en todos los casos de zonas medias-bajas y bajas el ancla es un autoservicio, como alguna del Grupo Wal-Mart o Soriana. Las plazas que están en zonas de transición por lo general tienen una mezcla de los dos tipos de anclas, es decir, departamentales y de autoservicio, que es el caso de Parque Tezontle en Iztapalapa, Delta en Benito Juárez, Fórum Buenavista en Cuauhtémoc, entre varias más.

\section{Etapas del surgimiento de los centros comerciales}

La inversión que se realiza con los grandes cc también tiene estrecha relación con las etapas de crisis en el país. Al igual que en el censo total, la época de menor crecimiento fue durante la década de 1990, en especial desde 1994 hasta 1998, ya que en esos años solo se inauguraron tres malls: Plaza Inbursa, de Grupo Carso; Mundo E, de Frisa; y Pabellón Bosques, localizados en zonas económicas medias-altas. Es decir, solo un grupo de desarrolladores con un gran potencial de capital pudieron sobrellevar las crisis económicas, aunque todas ellas fueron ya hacia finales de la década, además de que la apuesta era localizarlos en lugares donde aparentemente existía la certeza de éxito comercial.

Durante los sexenios federales panistas (2000-2006 y 2006-2012), los grupos urbanizadores crecen en número e importancia en todo el país. Se impulsan los grandes desarrollos urbanos e, incluso, se incentivan (Gráfica 4). Aunque pudieran existir algunas diferencias con los gobiernos perredistas en la Ciudad de México, pero no así con los priistas del Estado de México, donde los gobiernos local y federal trabajaban en coordinación.

Se identifican cuatro grandes etapas en la construcción de plazas comerciales: de 1969 a 1989, que marca el inicio de este tipo de comercios en general en el país, aunque durante la década de 1980 el avance de los cc se vuelve más lento y prácticamente dentro de los límites del Distrito Federal; la segunda etapa comprende entre 1990 y 1999, la cual se caracteriza por ser la época de consolidación de las plazas, ya que si bien fue lenta hubo un incremento constante; la tercera fue del año 2000 a 2009, que muestra una época de expansión, la cual se acentúa después de 2006; y la cuarta, después de 2010, en la que se incluyen los nuevos desarrollos que fueron proyectados hasta el año 2019 (Mapa 3; Gráfica 5).

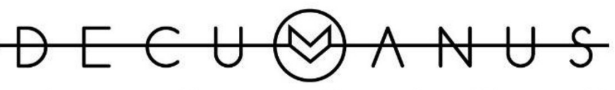

REVISTA INTERDISCIPLINARIA SOBRE ESTUDIOS URBANOS 
Gráfica 4. Aperturas por gobiernos partidistas por sexenios

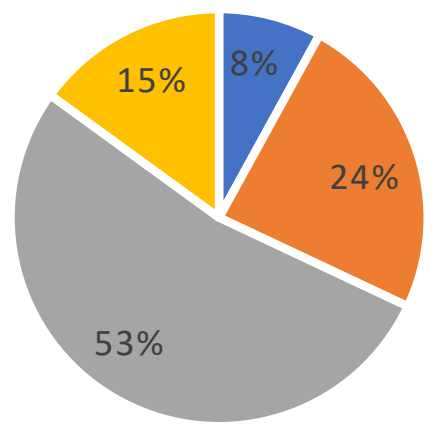

- Antes de 1982

- Gobiernos panistas 2000-2012
- Gobiernos priístas Entre 1982 y 2000

- Gobierno prí́sta de 2012 - 2018

Fuente: elaboración propia, a partir del levantamiento del censo propio.

Gráfica 5. Apertura de centros comerciales por década en la ZMCM

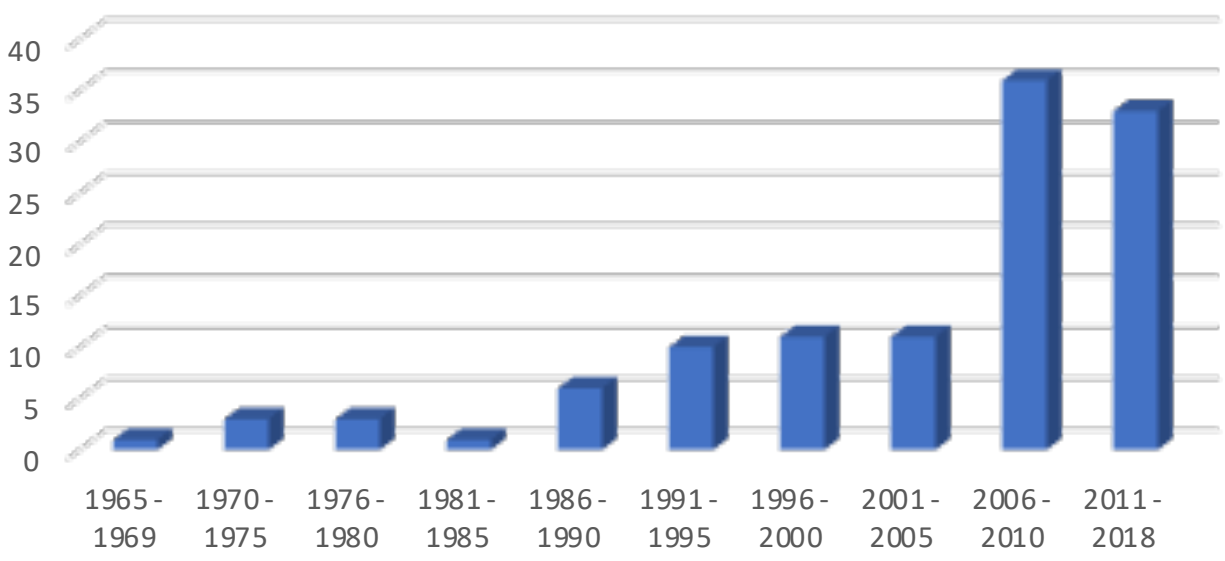

Fuente: elaboración propia, a partir del levantamiento del censo propio.

La primera etapa es desde la construcción del primer cc en 1969, Plaza Universidad, hasta el año de 1989. En este periodo se edificaron once: cinco en el Distrito Federal, en el poniente, centro y sur, y seis en el Estado de México, que se ubicaron en municipios del norte y el oriente. Desde esta etapa, se puede identificar que la mayor densidad de plazas se localizará del centro al poniente de la ciudad, mientras que al oriente serán dispersas.

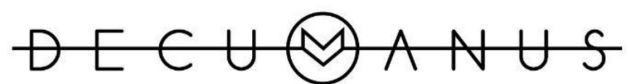

REVISTA INTERDISCIPLINARIA SOBRE ESTUDIOS URBANOS 
Mapa 3. Centros comerciales por periodos de apertura

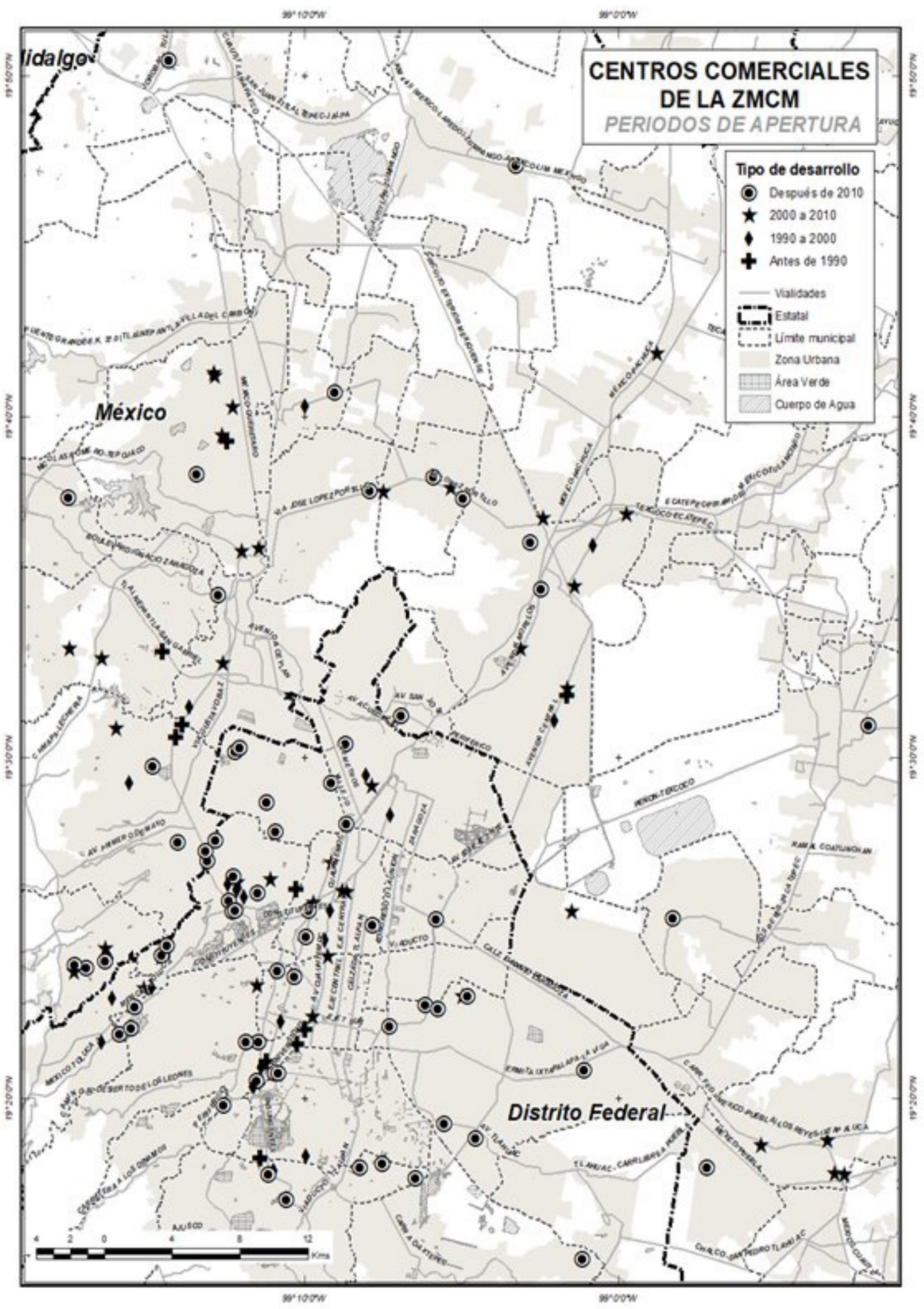

Fuente: elaboración propia, a partir del levantamiento del censo propio.

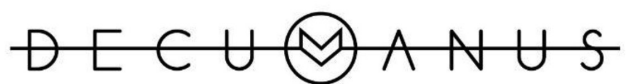

REVISTA INTERDISCIPLINARIA SOBRE ESTUDIOS URBANOS 
Desde 1990 y hasta 1999, se viven diferentes procesos, aunque en general se tiene un auge en la construcción de cc. En este lapso, se edifican veintidós plazas, la mitad hasta 1993, de las cuales nueve son dentro del entonces Distrito Federal, localizadas del centro hacia el poniente. En los siguientes cuatro años, se abren solo cinco en toda la ZMCM, todas también al poniente, mientras que las que ya existían atravesaban por severos problemas económicos, por lo que optaron por modificar su rubro u oferta; por ejemplo, Plaza Galerías, cuyos dueños deciden modificar el rubro y convertirlo en un medio difusor del espectáculo.

Dentro de este periodo, se da el cambio de administración en el Distrito Federal, en el que se establece la elección de un jefe de gobierno en 1997, que fue Cuauhtémoc Cárdenas, ${ }^{2}$ que surgió de un partido reconocido como de izquierda. Mientras que, en el Estado de México, durante todo este lapso han tenido administraciones priistas. Esto se volverá fundamental, debido a que la mejora urbana y el auge terciario en la ZMCM se dan bajo las administraciones perredistas. La zona norponiente del Estado de México comienza a ser significativa en la construcción de estas plazas, así como también Polanco y Santa Fe.

A partir del año 2000, se consolida la explosión de Cc en la ZMCM, primero en el Estado de México y después en la capital de la república. Hasta 2005, se construyeron trece centros comerciales, de los cuales ocho fueron en el estado mexiquense, siete de ellos al norponiente, mientras que en la Ciudad de México las nuevas plazas se ubican al centro-poniente.

Desde el año 2006, cuando concluye la segunda administración perredista en la Ciudad de México, la edificación se vuelve completamente dispersa, aunque hasta el año 2010 es el Estado de México el que abarca un mayor número de plazas nuevas. Hasta 2010 se inauguran veinticinco plazas, siete en la Ciudad de México y dieciocho en la zona conurbada, la mayoría de ellas en el año 2007, es decir, durante los periodos administrativos del perredista Marcelo Ebrard en la Ciudad de México y del priista Enrique Peña Nieto en el Estado de México.

El último gran periodo puede dividirse en dos: en donde se incluyan los cc ya inaugurados y los nuevos proyectos. Durante 2010 al 2013 se confirma la tendencia creciente de inaugurar plazas con treinta y seis nuevas. A partir del año 2014, se inicia una nueva etapa de masificación, ya que, al hacer un corte, hasta 2019 se tenían proyectadas, al menos, otras ocho plazas, seis dentro de los límites del otrora Distrito Federal, todas ellas con localización completamente dispersa. Además de que se reinvierte en remodelaciones o ampliaciones de plazas ya existentes, es también la etapa en que va a existir una mayor diversificación de los proyectos.

En la perspectiva de los constructores, la tendencia de crecimiento no se detiene, sino que, por el contrario, tienen previsto una mayor cantidad de terreno destinado a estos comercios, precisamente desde el año 2014, ya que este es considerado como el mejor en toda Latinoamérica en cuanto a proyectos concluidos, iniciados e inversión recaudada, además de que la tendencia es mejorar (Rodríguez, 2015). Es hasta después del año 2000 que se inicia el proceso de construcción de cc en el oriente de la ciudad. Las zonas ya consolidadas continúan en crecimiento. También, después del año 2000, es que a México

2 La administración de Cárdenas fue por un periodo de tres años, de 1997 a 2000; a partir de la segunda elección el periodo es ya de seis años.

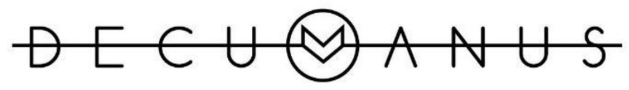

REVISTA INTERDISCIPLINARIA SOBRE ESTUDIOS URBANOS
Núm. 7. Vol. 7. Mayo 2021-Octubre 2021. Instituto de Arquitectura, Diseño y Arte. Universidad Autónoma de Ciudad Juárez. ISSN: 2448-900X 
llega un concepto de cc de lujo llamado fashion mall, el cual se inicia en Santa Fe y después se diversificó en Jalisco con Plaza Cibeles y Andares, en Mérida con Kukulcán Plaza y en la Ciudad de México con Antara (Rodríguez, 2015).

Este aumento también se ha expresado en la diversificación de empresas que invierten en el sector inmobiliario de cc, ya que anteriormente quienes invertían eran principalmente familias con el capital suficiente, mientras que ahora son diversos accionistas que conforman una gran variedad de compañías, además de que ingresan al sector empresarios que se dedicaban a otros rubros, como el caso de Grupo Gigante, que poco a poco se adentró en la cuestión urbana, por lo que junto con Danhos construyen Parque Delta, que es de los modelos de mayor éxito, lo que generó que Grupo Gigante se deshiciera de sus tiendas de autoservicio y se dedicara solo al rubro urbano.

\section{Centros comerciales: políticas y reglamentos}

El avance e inversión inmobiliarios van ligados a las reglamentaciones gubernamentales. Lulle y Paquette (2007, p. 343) explican que en el Programa de Desarrollo de 1987 no se hace referencia a los $\mathrm{Cc}$, es decir, es una etapa en la que ya existe un auge de los grandes malls en la ZMCM, pero no había ninguna reglamentación que tratara de legalizarlos; esto ocurrió hasta 1996 cuando finalmente se da un reconocimiento gubernamental a estas obras urbanas, aunque solo se reconocen catorce en el Distrito Federal. Con esto se reconoce la importancia que tienen ya estas estructuras en cuestión comercial y urbana, aunque no existió una reglamentación que tratara de limitarlos o regularlos.

López (2006, p. 159) menciona otro punto trascendental en su estudio: se les da importancia central a las tiendas ancla, lo cual será en dependencia de la zona económica donde se edifique el cc; por ello estas serán diferentes y las tiendas más lujosas estarán en las partes de la ciudad donde más recursos económicos se tienen. Con esto también el empresario inmobiliario pudo entrar de una forma más organizada y planificada a las zonas conocidas como de bajos recursos, ya que edificaban grandes bodegas para destinarlas a tiendas de autoservicio sin las departamentales que son altamente costosas. Además que se garantiza el éxito de la plaza, porque se cubren las necesidades de la población que circunda el nuevo cc. Después del sexenio de Salinas de Gortari, se inicia la edificación de los CC en las zonas oriente, norte e, incluso, centrales de la ZMCM, con lo cual este proceso de tercerización adquirió una cobertura casi total en toda la ciudad; es decir, que ya entrado el neoliberalismo en el país, se transforma el tipo de hacer ciudad por parte del capital inmobiliario y, por ende, de construir cc; se modificó y se empezó a incluir a todos los sectores sociales, aunque de forma parcial y selectiva. Una de las formas en las que se cambian las características es en la forma de conseguir lugares para construir los $\mathrm{Cc}$ - al menos en el interior de la ciudad han sido las reglamentaciones.

Lulle y Paquette (2007, p. 344) explican que en el Programa General de Desarrollo Urbano del Distrito Federal de 2003, se consideraban los nuevos cc como una de las causantes del crecimiento de la periferia de la ciudad. Este programa, que se publicó en la Gaceta Oficial el día 31 de diciembre de 2003 cuando López Obrador era jefe de Gobierno, da muestras de la preocupación de la expansión urbana y del crecimiento descontrolado, en especial "en las delegaciones periféricas" (Gaceta Oficial del Distrito Federal, 2003).

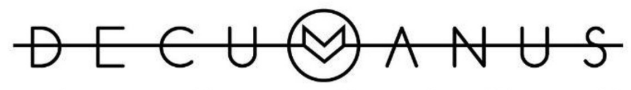

REVISTA INTERDISCIPLINARIA SOBRE ESTUDIOS URBANOS 
Mientras que, en otro punto, el documento confirma a nivel gubernamental unas hipótesis de las que parte la presente investigación: que el sector inmobiliario es causante de la producción de un espacio acorde a sus intereses y no a las necesidades sociales.

En ese programa también se hace un breve recorrido de la actividad comercial en el Distrito Federal y se asume la importancia que ha tenido la actividad inmobiliaria, la cual, menciona el documento, ha tenido un comportamiento inestable "derivado de las crisis sucesivas, sin detonar una etapa sostenida de expansión de la industria de la construcción", aunque ha tenido "breves periodos de auge en la década de los noventa vinculados con la especulación derivada de la apertura comercial" (Gaceta Oficial del Distrito Federal, 2003). Este periodo de inestabilidad fue provocado por la caída de los mercados internos y de los poderes adquisitivos de la población, además del crecimiento inmobiliario que desencadenó el encarecimiento del suelo y una disminución en la construcción de vivienda social (Gaceta Oficial del Distrito Federal, 2003).

La inestabilidad que hasta ese momento se había tenido en el sector inmobiliario, junto con la etapa de desindustrialización del país, provocaba un efecto negativo en la generación de empleos, pues en el sexenio de Zedillo (1994-2000) la tasa de población ocupada bajó alrededor de 55 \%, lo que también benefició un incremento acelerado del

proceso de cambio en los patrones de su actividad comercial, que se expresa en la proliferación de mega CC, tiendas departamentales, autoservicios y franquicias. Estos van desplazando a los centros tradicionales de abasto (mercados públicos, negocios de abarrotes, tortillerías, panaderías, etc.) que no tienen recursos suficientes para competir con este tipo de comercio, controlado por monopolios nacionales y extranjeros. Este fenómeno margina a los productores nativos, modifica los patrones de consumo y causa alteraciones en el funcionamiento urbano. [...] Así se constituyen dos circuitos comerciales paralelos y aislados que abastecen, en un caso, a las clases medias y altas y, en otro, a los sectores de más bajos ingresos, pero que no armonizan en un sistema comercial articulado e integral (Gaceta Oficial del Distrito Federal, 31 de diciembre de 2003, p. 14).

En el programa se tiene, entonces, la conciencia de que el surgimiento de nuevos cc grandes, o megaproyectos, además de otras urbanizaciones, acarrea consecuencias sociales y económicas que colaboran en generar la separación social entre la comunidad. Aunque eso se marca como un punto a prestar atención, pues ese fenómeno aumentaba en la década de 1990, no se realizaron las acciones pertinentes o, al menos, estas no funcionaron.

También Lulle y Paquette (2007, p. 344) coinciden y hacen evidente que el programa consideraba la gravedad de la saturación de los cc, como el incremento vehicular y de estacionamientos, transformación en el uso del suelo y alteración de espacios aéreos, cambios urbanos y eliminación de los espacios públicos. Sin embargo, aunque el diagnóstico es profundo las acciones que se realizaron o que se planearon no limitaron o reglamentaron siquiera la construcción de los grandes malls, pues los empresarios inmobiliarios han seguido construyendo sin ningún tipo de limitante o de restricción; incluso, en la administración distrital anterior es cuando más permisos de construcción se aprobaron,

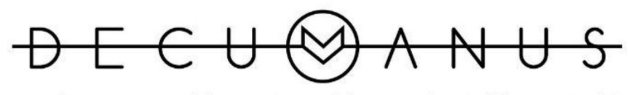

REVISTA INTERDISCIPLINARIA SOBRE ESTUDIOS URBANOS
Núm. 7. Vol. 7. Mayo 2021-Octubre 2021. Instituto de Arquitectura, Diseño y Arte. Universidad Autónoma de Ciudad Juárez. ISSN: 2448-900X 
a pesar de que ahora existan más reglamentos o programas que intentan frenar el avance terciario.

Lulle y Paquette (2007, p. 348) describen que todo evidencia que en esta etapa del capitalismo las "autoridades han sido rebasadas por el mercado" y también por el interés inmobiliario, que define y hace la ciudad. Los intentos de limitar los permisos para los Cc, se han mantenido en propuestas y pedimentos por parte de algunos sectores políticos de la Ciudad de México, los cuales señalan las complicaciones que tiene la ciudad; por ejemplo, esto ocurrió en 2008 cuando un sector de la Asamblea Legislativa del Distrito Federal solicitaba que se limitaran las construcciones de Cc, pues estas provocaban que los mercados tradicionales y centrales de abastos fueran superados y pudieran llegar a la quiebra ante la imposibilidad de competir con los grandes cc.

Lejos de limitar las licitaciones, el gobierno de Ebrard presumía, durante el sorteo previo al Mundial de Futbol a realizarse en Sudáfrica en 2010, que en los límites de la Ciudad de México existían veinte grandes cc, que, según Alejandro Rojas Durán, secretario de Turismo en ese momento, eran un atractivo de la ciudad para el turismo extranjero. En la inauguración de Parque Tezontle, los representantes del gobierno distrital y de la delegación Iztapalapa presumían la inversión privada, la más grande en esa zona de la ciudad con el mismo equipamiento y arquitectura que los grandes cc de otras áreas de la ciudad.

Estas acciones ponen de manifiesto que las autoridades gubernamentales impulsan en la ciudad la competitividad que le permita verse como ciudad global; también se le otorga a la inversión privada inmobiliaria un papel fundamental en el desarrollo urbano. La construcción de cc en los Cetram también es una muestra del doble discurso del gobierno capitalino, pues, por un lado, algún sector pide que este tipo de estructuras se limite, y por otro, que se impulse, porque se ven como las únicas formas de realizar inversión y mejoras en las zonas donde se localizan los antiguos paraderos.

El Programa General de Desarrollo Urbano del Distrito Federal (PGDUDF) de 2003 continuó hasta el año 2012 cuando se le trataron de hacer algunas mejoras con el propósito de hacer una ciudad más ordenada y democrática (Programa General de Desarrollo Urbano, 2012). En este mismo año entran en vigor otros programas que tratan de lograr una ciudad con mayor ordenamiento; uno de ellos es el Programa de Ordenación de la ZMCM, que entra en vigor en ese mismo año, el cual trata de hacer de esta una "metrópoli equitativa, sustentable, competitiva y gobernable" (Programa General de Desarrollo Urbano, 2012). En la elaboración de estos, el avance acelerado de la construcción de inmuebles se convirtió en un punto de preocupación para algunos sectores gubernamentales, pues parecía que toda la inversión se realizaba sin que existiera algún impedimento legal, por lo que se pedía que se verificaran las nuevas construcciones (Programa General de Desarrollo Urbano, 2012).

Desde el PGDUDF de 1996 había la intención de que estas nuevas estructuras urbanas tendientes a la tercerización conformaran nuevos subcentros, pero no en los lugares donde se necesitaban, que eran zonas pertenecientes a las clases medias y bajas, sino en las áreas de la ciudad con mayores niveles adquisitivos, debido a que los intereses privados de construcción estaban destinados hacia sectores altos y medios altos (PGDUDF, 1996, p. 76; en: Lulle, \& Paquette, 2007, p. 349).

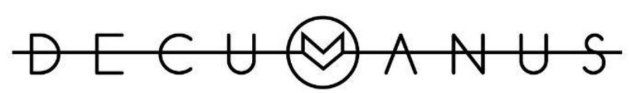

REVISTA INTERDISCIPLINARIA SOBRE ESTUDIOS URBANOS
Núm. 7. Vol. 7. Mayo 2021-Octubre 2021. Instituto de Arquitectura, Diseño y Arte. Universidad Autónoma de Ciudad Juárez. ISSN: 2448-900X 
En el Estado de México los reglamentos y planeaciones urbanas no han buscado ser limitantes o controladores de los cc, sino que, por el contrario, en varias acciones se les propicia e incita. Además, existen diferentes medidas urbanas en esta entidad, ya que se consideran, al menos, tres zonas: Valle de Toluca; Valle Cuautitlán-Texcoco; y el resto de los municipios del estado. El primero se considera como una estructura urbana propia, mientras que el segundo está en relación completa con la Ciudad de México; por lo que las reglamentaciones son dispares.

Como diagnóstico, el gobierno mexiquense considera que la concentración urbana del Valle Cuautitlán-Texcoco es una extensión de la Ciudad de México, lo que ha provocado desequilibrios regionales urbanos, pues la urbanización corresponde a las necesidades de la capital y no de los municipios, por lo que el sistema urbano y organizacional es para generar centros de menor tamaño y dispersos. La urbanización dispar en la zona conurbada ha justificado la construcción de los Cc, ya que son considerados dentro de los planes de ordenamiento como necesarios para el equipamiento, desarrollo y estrategias de crecimiento económico (Gobierno del Estado de México, 2008).

Según Lulle y Paquette (2007, p. 349), la planeación urbana gubernamental responde también a la etapa económica en que se vive, pues en la actualidad las reglamentaciones son más laxas y flexibles, y por un tipo de urbanización con proyectos más ágiles y en los que se mezcle la participación de capital privado con el público. El inicio del neoliberalismo en México significó cambios en las planeaciones urbanas del Distrito Federal, aun cuando era Departamento del Distrito Federal a cargo del partido en el gobierno federal, ya que desde esa época se comenzaba a brindar una apertura hacia la inversión del sector inmobiliario, al que solo se le impedía la construcción de megaproyectos que podrían atentar contra la estructura urbana que predominaba. Esta política continuó durante la primera administración perredista (1997-2000) con Cuauhtémoc Cárdenas (Pradilla, 2004).

Mientras que durante la administración de López Obrador, se impulsó el llamado Bando Informativo Número 2, que pretendía frenar el crecimiento desordenado de la ciudad con el objetivo de que el gobierno local estaría por encima de los grupos urbanizadores, por lo que se prohibió la construcción de grandes cc en las delegaciones Álvaro Obregón, Coyoacán, Cuajimalpa, Iztapalapa, Magdalena Contreras, Milpa Alta, Tláhuac, Tlalpan y Xochimilco, es decir, al oriente y sur de la ciudad principalmente, y se incentivaría la construcción hacia el centro de la Ciudad de México. Si bien esto no significó un cambio rotundo en las construcciones de las grandes plazas, ya que durante este periodo se construyen tres y dos más en 2007; aunque de estas últimas los permisos se otorgaron durante la administración obradorista, parecería que sí funcionó la intención de atraer inversión hacia el centro de la ciudad, ya que solo Parque Tezontle se edificó fuera de esta zona, en Iztapalapa, la cual fue abierta hasta 2007, es decir, ya en el periodo gubernamental siguiente. Fue desde el mandato de López Obrador que se estrechó la relación entre el gobierno y las empresas para la inversión inmobiliaria.

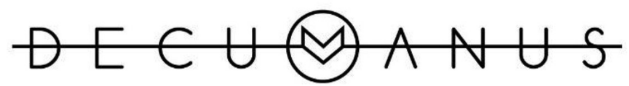

REVISTA INTERDISCIPLINARIA SOBRE ESTUDIOS URBANOS 


\section{Gráfica 6. Construcción de centros comerciales por periodo de gubernatura en el Distrito Federal desde 1997}

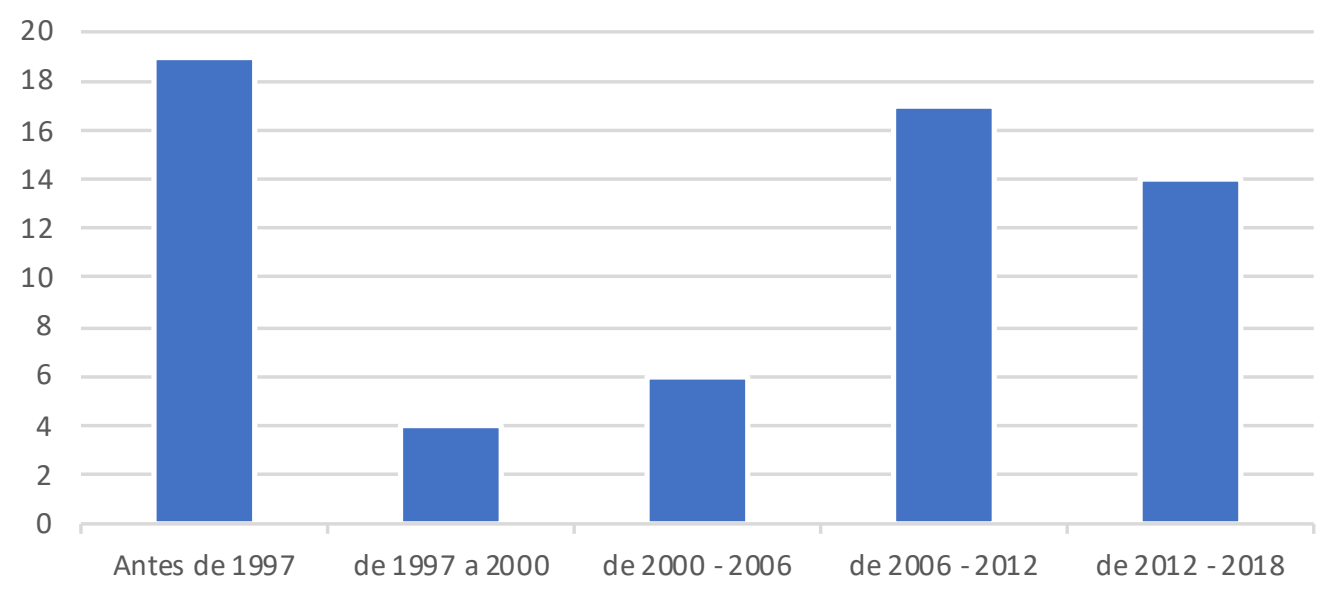

Fuente: elaboración propia, a partir del levantamiento del censo propio.

Pradilla (2008, p. 50) nuevamente realiza un análisis en el que menciona que el Bando Informativo Número 2 no impidió que los grandes cc se siguieran construyendo en las delegaciones centrales. Y va más allá al mencionar que el siguiente jefe de Gobierno, Marcelo Ebrard (2006-2012), no limitó su crecimiento. A esto se debe agregar que en la administración de Miguel Mancera (2012-2018) no existió prácticamente ninguna limitación (Gráfica 6).

\section{Conclusiones}

El capitalismo busca en todo momento producir espacios que le sean afines, lo que ayudará a reproducir ideas, comportamientos y justificar inversiones o el avance del capital. Los cc son parte sustancial de esta proyección del sistema económico. Si bien se puede hablar de que la figura de un lugar donde se aglutinan diversas formas de comercio existe desde tiempos antiguos, las características actuales que tienen estas infraestructuras urbanas son representativas del neoliberalismo.

Las empresas urbanas buscan casi a cualquier precio un terreno en una zona que les permita generar ganancias. En esa búsqueda del lugar puede existir una suplantación de alguna actividad o de elementos icónicos históricos, como Cuicuilco, o simplemente se evidencia la superación de una etapa económica como el industrial. El cc es difundido como un símbolo de modernidad en la ciudad que pretende ser vista como global, por lo que elimina todo rasgo que no contribuya a esta característica. Eso provoca que se pierda identidad dentro de la urbe y que se tenga cierta alineación con el resto de los centros urbanos en el mundo, y que las características que se le van imponiendo a la ciudad no sean acordes con las necesidades de la población, sino del gran capital.

Como se mencionó al inicio del trabajo, el neoliberalismo tiene como característica que el sistema gubernamental otorgue al capital privado las principales tareas. Esto es también notorio en los cc, ya que estos serán promocionados por los distintos gobiernos

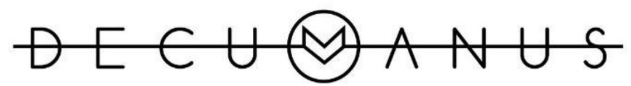

REVISTA INTERDISCIPLINARIA SOBRE ESTUDIOS URBANOS 
como una forma de generar empleo, el cual será precario y sin prestaciones sociales; de solucionar problemas sociales, como la violencia o la inseguridad, ya que al impulsar cc se genera la idea de que la mejora en infraestructura beneficiará a la sociedad, debido a que habrá mayor vigilancia, limpieza y acceso a diversas zonas; incluso, por algunos gobiernos de la ZMCM son impulsados como desarrolladores urbanos y atrayentes de inversión. Es por ello que la legislación es, al menos, permisiva al respecto si no es que los mismos gobiernos buscan soluciones en las mismas empresas urbanas.

Hoy en día la edificación de cc es prácticamente sinónimo de generación de plusvalía, por lo que el número de empresas que se interesan en ingresar a este rubro aumentan constantemente. Ya sea que estas cambien de rubro, como Gigante, o surjan nuevos inversionistas. Todas las compañías tienen objetivos distintos y alianzas estratégicas con diversos sectores económicos, por lo que el resultado será la producción de un espacio urbano neoliberal donde se privilegia la generación de plusvalía por encima de la solución de problemáticas sociales.

El éxito que tienen los cc se debe a la forma de operar, donde las empresas constructoras se adueñan de una porción del terreno para edificar sus obras y, a partir de ahí, generar una renta que les permita controlar el espacio y obtener ganancias. Y no permitir ninguna actividad que pueda ser ajena a la actividad que ellas mismas pretenden.

Por lo tanto, las empresas constructoras de cc han ayudado a edificar una ciudad neoliberal, por lo que la tendencia hacia construir cada vez más cc continúa, a pesar de los cambios de gobierno federal y locales, y de las características internacionales que parecieran ir en un camino distinto al que se tiene en la ZMCM.

\section{Referencias}

Cruz, F. (2008). Megaproyectos comerciales en la Ciudad de México. Esenc. Esp., 27. IPN.

Escudero, L. (2008). Los centros comerciales. Espacios postmodernos de ocio y consumo (Colección Monografías). Ediciones de la Universidad de Castilla-La Mancha.

Gaceta Oficial del Distrito Federal (2003, 31 de diciembre). Decreto por el que se aprueba el Programa General de Desarrollo Urbano del Distrito Federal. Recuperado en abril de 2017, de http://cgservicios.df.gob.mx/prontuario/vigente/402.pdf

Gasca, J. (2017). Centros comerciales de la Ciudad de México: el ascenso de los negocios inmobiliarios orientados al consumo. Eure, 43(130).

----- (2017). Los centros comerciales en la Ciudad de México: difusión espacial y efectos en la reestructuración urbana. En: J. Gasca (Coord.), Espacios del consumo y el comercio en la ciudad contemporánea (pp. 57-93). DGAPA.

Gobierno del Estado de México (2008). Plan Estatal de Desarrollo Urbano. Recuperado en junio de 2021, de http://seduv.edomexico.gob.mx/dgau/pdf/PEDU.pdf

Harvey, D. (1990). Los límites del capitalismo y la teoría marxista. Fondo de Cultura Económica.

----- (2005). El arte de la renta: la globalización y la mercantilización de la cultura. En: D. Harvey, \& N. Smith, Capital financiero, propiedad inmobiliaria y cultura. Museu d`Art Contemporani de Barcelona/UAB de Bellaterra.

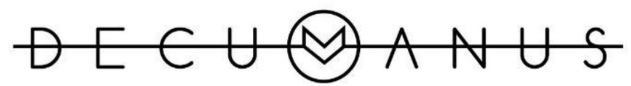

REVISTA INTERDISCIPLINARIA SOBRE ESTUDIOS URBANOS
Núm. 7. Vol. 7. Mayo 2021-Octubre 2021. Instituto de Arquitectura, Diseño y Arte. Universidad Autónoma de Ciudad Juárez. ISSN: 2448-900X 
Jaramillo, S. (2008). Hacia una teoría de la renta del suelo urbano. Universidad de Los Andes (Col. CEDE 50 años; 2. ${ }^{a}$ ed.).

López, L. (1999). Centros comerciales: espacios que navegan entre la realidad y la ficción. Nuestro Tiempo.

----- (2006). Centros comerciales, recintos fortificados. Veredas, 7(12), 147-163.

Lulle, T., \& Paquette, C. (2007). Los grandes centros comerciales y la planificación urbana. Un análisis comparativo de dos metrópolis latinoamericanas. Est. Dem. Urb., 22(2), 337-361.

Pradilla, E. (2004). Ciudad de México: Los Caminos de la Privatización de lo Urbano. En Ciudades 64, octubre - diciembre, RNIU, Puebla.

----- (2008). Zona Metropolitana del Valle de México: de la centralidad a la red de corredores terciarios. SCRIBD.

----- (2012). La economía y las formas urbanas en América Latina. En: B. Ramírez, \& E. Pradilla (2012), Teorías sobre la ciudad en América Latina, Volumen 1. UAM-Xochimilco.

Pradilla, E., Márquez, L., Carreón, S., \& Fonseca, E. (2008). Centros comerciales, tercerización y privatización de lo público. Ciudades, 79. RNIU.

Programa General de Desarrollo Urbano del Distrito Federal (2012). issuu. Recuperado en abril de 2016, de http://issuu.com/politicaspublicas/docs/pgdudf/112

Robert, A., \& Messias, W. (2009). Geografía crítica. La valorización del espacio. ITACA.

Rodríguez, J. (2015). Perspectivas 2015 para centros comerciales en Latinoamérica. Inmobiliare, 87, 108-118. Recuperado en agosto de 2016, de http://inmobiliare.com/digital/ INMOBILIARE-87.pdf

Zárate, A. (1994). El mosaico urbano. Organización interna y vida en las ciudades. Cuad. Est., 13 (Serie Geografía). Cincel.

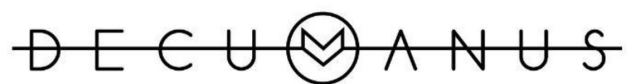

REVISTA INTERDISCIPLINARIA SOBRE ESTUDIOS URBANOS 